\title{
Design of Carbon Composite Driveshaft for Ultralight Aircraft Propulsion System
}

\author{
R. Poul, P. Růžička,. D. Hanus, K. Blahouš
}

This paper deals with the design of the carbon fibre composite driveshaft. This driveshaft will be used for connection between piston engine and propulsor of the type of axial-flow fan. Three different versions of driveshaft were designed and produced.

Version 1 if completely made of Al alloy. Version 2 is of hybrid design where the central part is made of high strength carbon composite and flanges are made of Al alloy. Adhesive bond is used for connection between flanges and the central CFRP tube. Version 3 differs from the version 2 by aplication of ultrahigh-strength carbon fibre on the central part. Dimensions and design conditions are equal for all three versions to obtain simply comparable results. Calculations of driveshafts are described in the paper.

Keywords: composite driveshaft, adhesive bond, filament winding, carbon composite, CFRP driveshaft.

\section{Introduction}

In our work we focused on design of lightweight drive shaft for connection of piston engine with axial flow fan.

This shaft has got the following design criterions. Obvious requirement is the sufficient strength and wall stability to withstand torsional moment of $500 \mathrm{Nm}$ which is estimated to be the peak one. Low weight is important for the propulsion system and aircraft overal weight. Bending stiffness high enough to allow the shaft to work in supercritical regime, but torsional stiffness low enough to allow the use of lighter shaft couplings are required. All these requirements can be fulfiled when composite material is used.

For our application the hybrid construction is chosen, where flanges are made of Al-alloy and central cylindrical part is made of carbon fibre reinforced epoxi resin. Connections between composite and metallic parts are accomplished using epoxi adhesive system.

Two different versions of composite shafts were produced to compare properties of them. Analytical solution of both shafts were done using classical lamination theory with the Puck s failure criterion. Finite element analysis of the cylin- drical shell and of the adhesive bond was also done. Both analytical methods were compared with experimental results.

This shaft is expected to be more useful for propulsion system than previously designed metallic version.

\section{Shaft description}

The driveshaft connects the fan rotor with driving engine. One shaft coupling is inserted at each end of the shaft to minimize the transfer of torque and rotation irregularities from engine to rotor. Our goal is to design the driveshaft with sufficiently low torsional stiffness to allow us to use lighter shaft couplings. This is possible when applying orthotropic mechanical properties of fibre reinforced composite.

Three different versions of the driveshaft were designed. First one is completely made of alluminium alloy. This shaft is used to compare "classical" design with composite solution. The greatest disadvantages of this design is complicated manufacturing and limitations to taylor shaft properties. Cylindrical part of the shaft version two is made of high strength carbon fibres with epoxi resin. Flanges made of alluminium alloy are adhesively bonded to the central composite part.
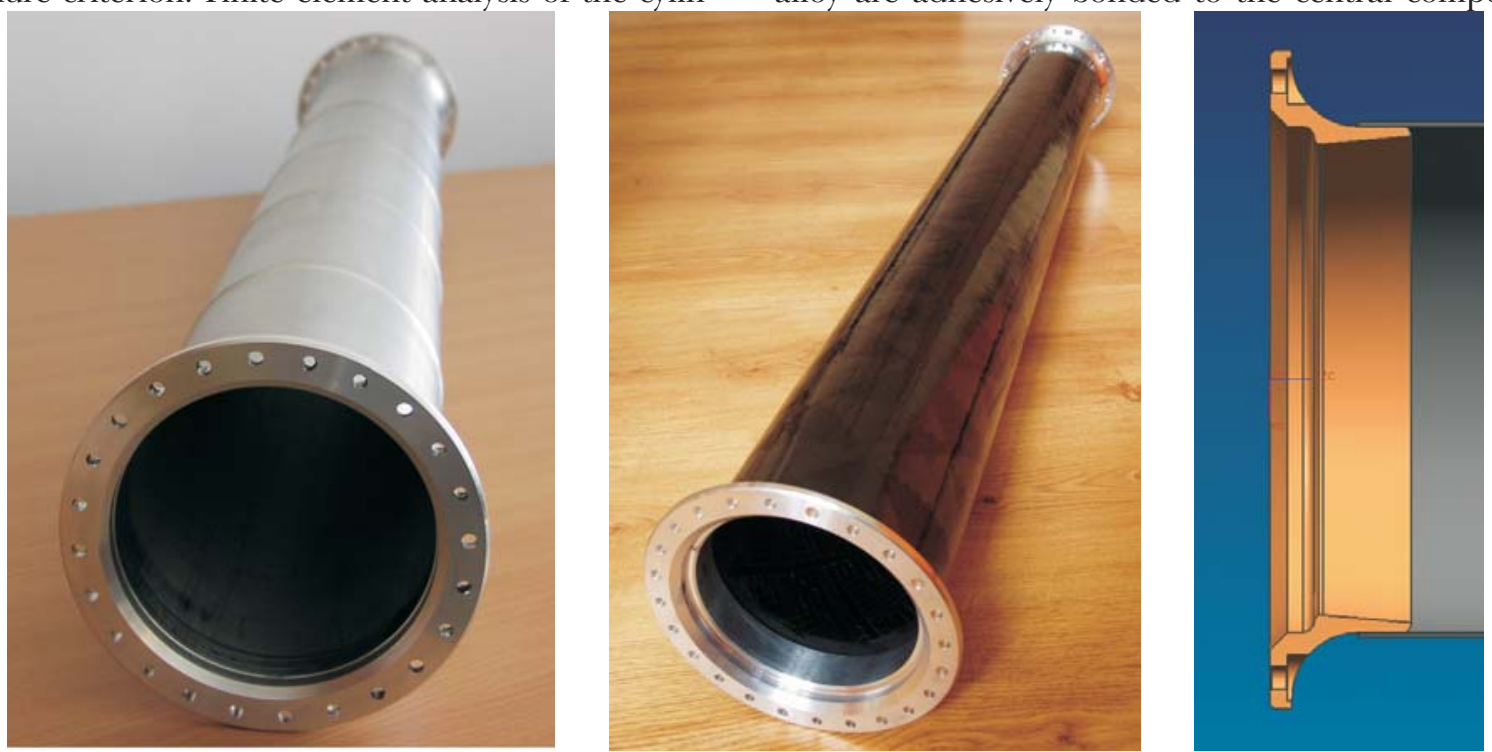

Fig. 1: Driveshaft version 1 (left) and version 2 (center). Detail of connection of flange with central section of versions 2 and 3 (right) 

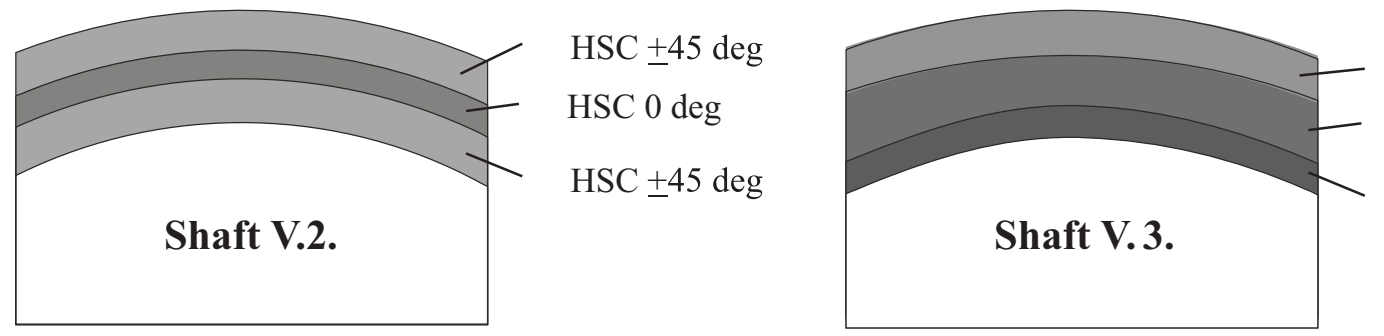

\author{
$\mathrm{HSC} \pm 34 \mathrm{deg}$ \\ HMC 0 deg \\ $\mathrm{HSC} \pm 85 \mathrm{deg}$
}

Fig. 2: Layups of carbon composite sections of shafts version 2 and 3; HSC means high-strength carbon (also called as standard-modulus carbon) and HMC means high-modulus carbon

This solution provides technological simplification despite more manufacturing steps are needed. Shaft version two did not take the need of low torsional stiffness into account. Driveshaft version three combines in its cylindrical part high and standard modulus fibres reinfoced plastics. In this design we obtaind high bending stiffness combined with low torsional stiffness. Technological demands are the same as for version two.

All three versions are of approximately the same dimensions to make them comparables. All shafts are of the lenth of $953 \mathrm{~mm}$. Internal diameter is $115 \mathrm{~mm}$ and wall thickness is approximately $1 \mathrm{~mm}$. Tollerance of the wall thickness of composite versions is higher because of the filament winding technology used.

\section{Design of composite sections of shafts}

Central, composite sections of driveshafts was designed by iterative method with reference to technological, dimensional and mechanical limitations given for the shaft. Filament winding technology was chosen for production of the shaft. This technology allowes us to specify the angle of winding in the range from 0 to 90 degrees where 0 degrees represents axial orientation of the reinforcement.

For estimation of mechanical properties we used classical lamination theory (CLT) which is expected to be sufficient for such a thin walled shell. CLT ommits off-plane deformations and works with the shell as with the Kirchhoff's plate. Micromechanical models was used to calculate the composite properties as result of properties of matrix and reinforcement.

Following formulas demonstrate dependancy of mechanical properties of composite on orientation of the reinforcement.

$$
E(\theta)=\frac{E_{L}}{\cos ^{4} \theta+\frac{E_{L}}{E_{T}} \cdot \sin ^{4} \theta+\frac{1}{4}\left(\frac{E_{L}}{G_{L T}}-2 v_{L T}\right) \cdot \sin ^{2}(2 \theta)}
$$$$
G(\theta)=\frac{E_{L}}{\left(1+2 v_{L T}+\frac{E_{L}}{E_{T}}\right)-\left(1+2 v_{L T}+\frac{E_{L}}{E_{T}}-\frac{E_{L}}{G_{L T}}\right) \cdot \cos ^{2}(2 \theta)}
$$

where: $E$

$$
\begin{aligned}
& G \\
& v_{L T}
\end{aligned}
$$$$
\theta
$$

is Young's modulus of composite, is shear modulus of elasticity, is Poisson's ratio, is angle between reinforcement direction and chosen mean axis of the material, subscript $L$ represents the direction along the reinforcement and

subscript $T$ represents the direction perpendicular to the reinforcement orientation.

Following layups are designed for shafts version 2 and 3 .

Both versions are expected to be loaded by torsional moment of $500 \mathrm{Nm}$. This value is given as the maximal one. No bending moment is applied. Torsional moment can cause three types of failure. Shear failure of the composite shell which is predicted by Puck's failure criterion. This criterion is applied on results of the CLT. Loss of wall stability can occur, if the wall bending stiffness is not sufficient. Third case of failure is the failure of adhesive bond between metallic flanges and composite section. This is analysed separately.

The loss of wall stability caused by torsional moment is analysed by the following formula:

$T_{x y}=\frac{\pi^{2}}{12}\left[\frac{e^{9}}{r_{0}^{3} L^{2}}\right]^{\frac{1}{4}} \cdot\left[\frac{E_{x}^{3} E_{y}^{5}}{\left(1-v_{x y} \cdot v_{y x}\right)^{5}}\right]^{\frac{1}{8}}$

where: $E \quad$ is Young's modulus,

$e \quad$ is the tube wall thickness,

$r_{0} \quad$ is radius of the tube midplane,

$L \quad$ is length of the tube,

$v \quad$ is Poisson's ratio,

$T \quad$ is the unit shear force calculated from the torsional moment and tube dimensions,

subscript $x$ represents the tube axial direction and subscript $y$ represents the tube tangential direction.

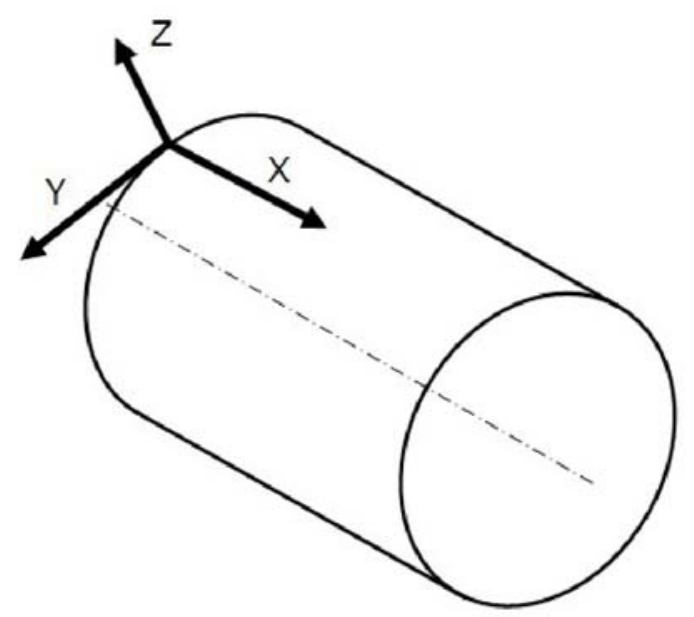

Fig. 3: Coordinate system used for stress analysis 

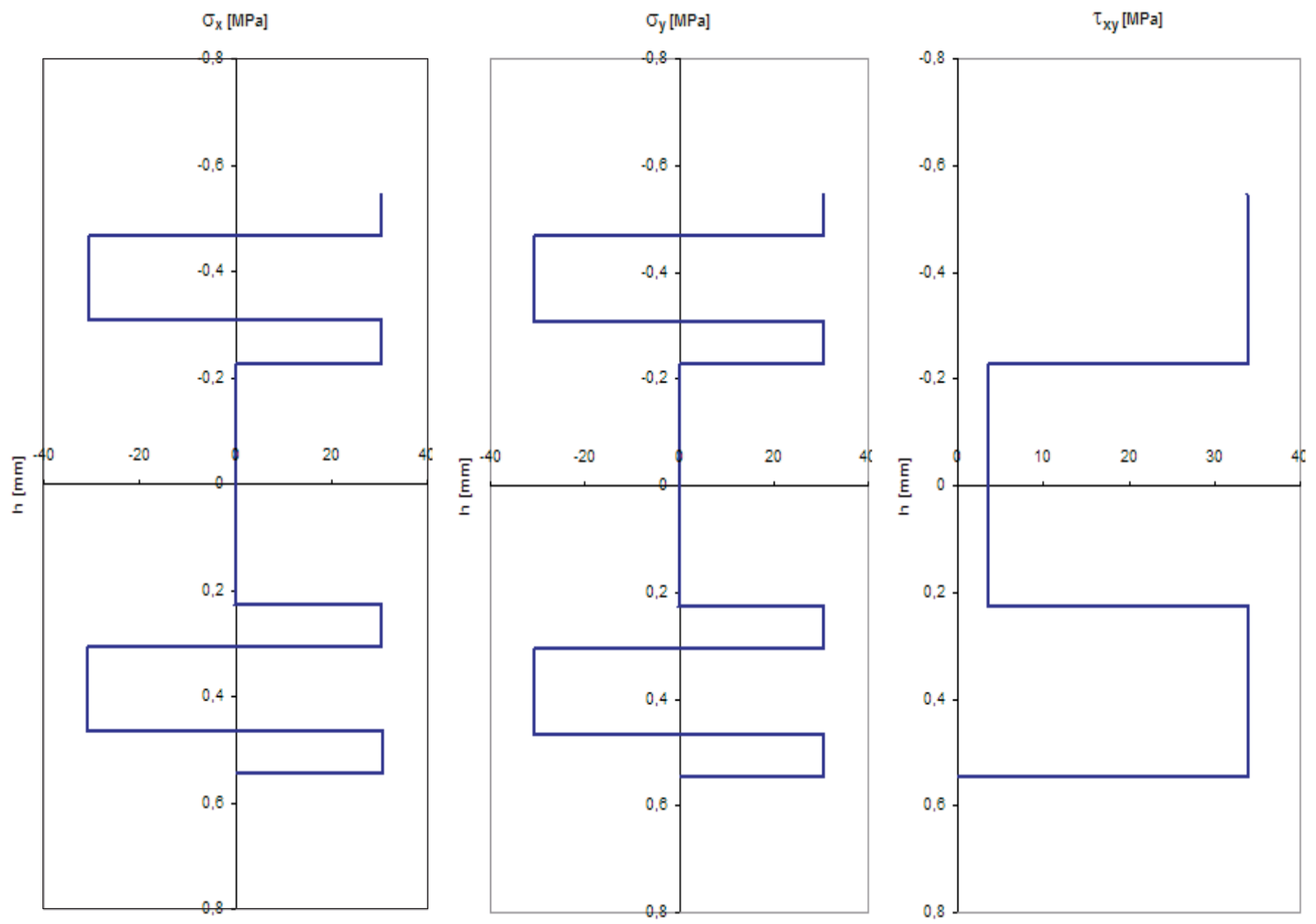

Fig. 4: Stress distribution in composite part of the shaft version 2. Torsional moment of $500 \mathrm{Nm}$ is applied. Subscript $x$ means axial direction, subscript $y$ means tangential direction.

The critical torsional moment is calculated from this formula for tubes version 2 and 3 as 429 and $1605 \mathrm{Nm}$ respectively.

Shear strength was analysed by the CLT software called LamiEx V3, which calculates stresses and deformations of laminate element. Puck's failure criterion was applied on cal- culated stresses to check if failure occures in the laminate when maximal torsional moment is applied. This software also calculates effective moduli of elasticity which can be then used for simplified calculations. These values we used to estimate bending and torsional stiffnesses of all shafts. Stress distribution in laminates is presented in Figs. 4 and 5.
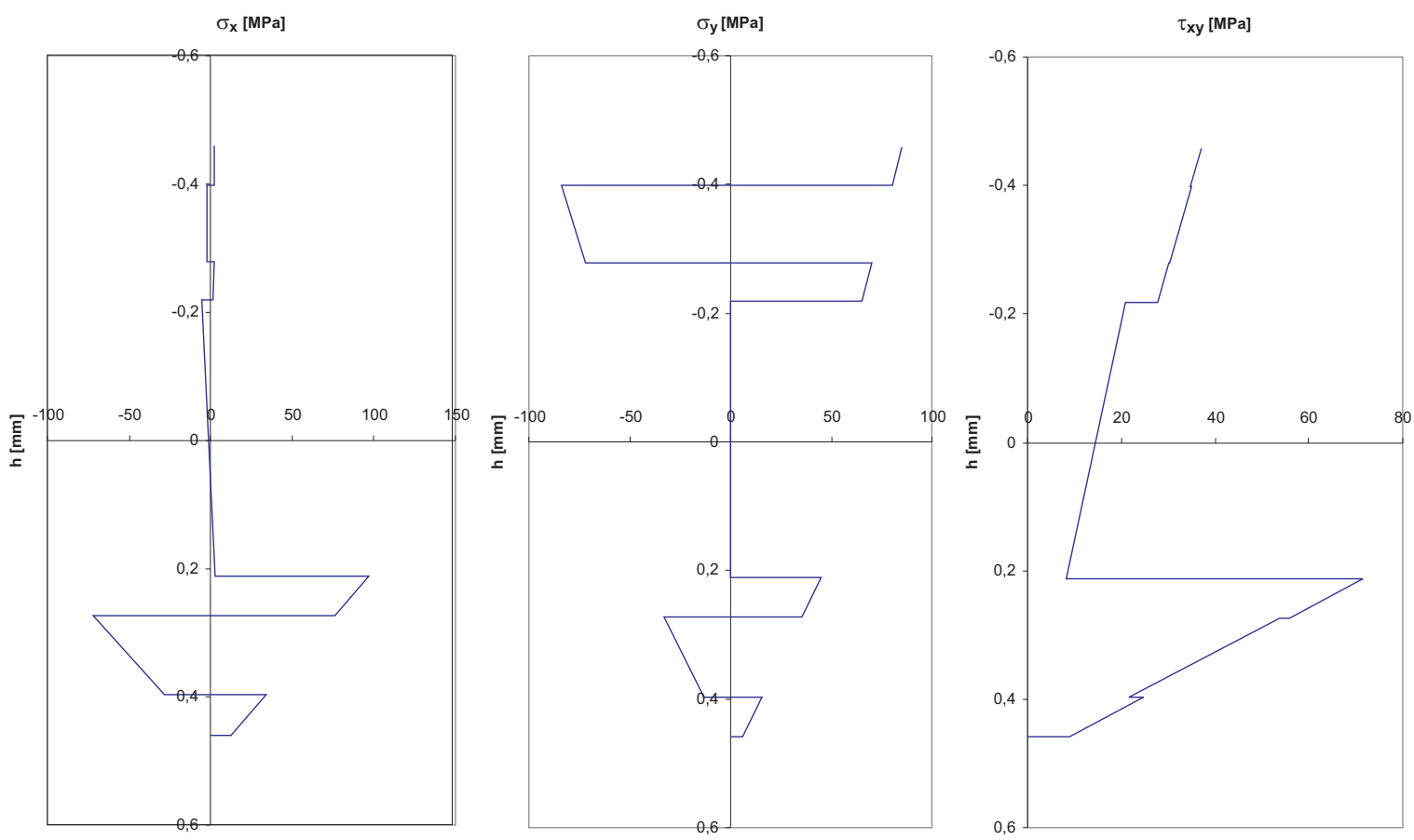

Fig. 5: Stress distribution in composite part of the shaft version 3. Torsional moment of $500 \mathrm{Nm}$ is applied. Subscript $x$ means axial direction, subscript $y$ means tangential direction. 


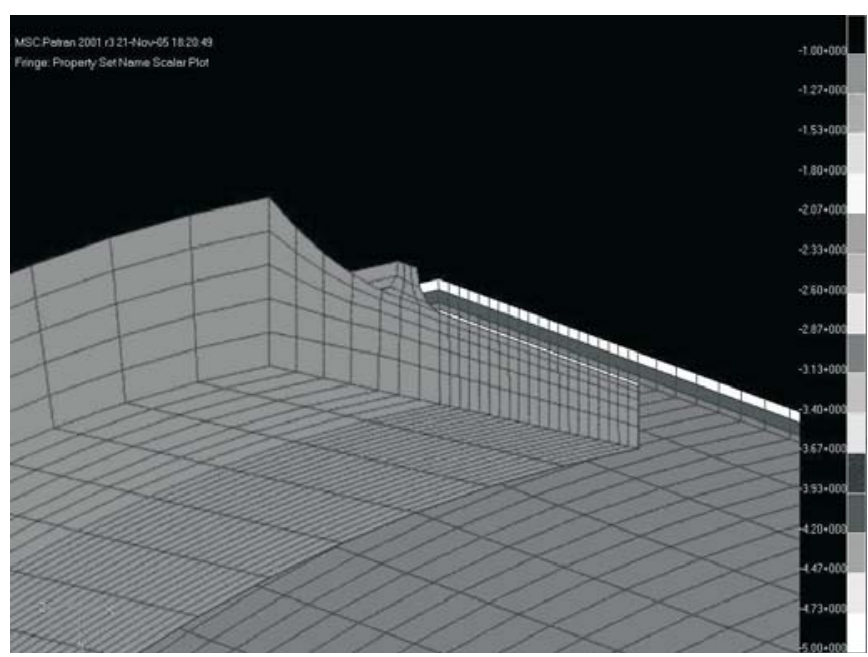

Fig. 6: Model of adhesive bond

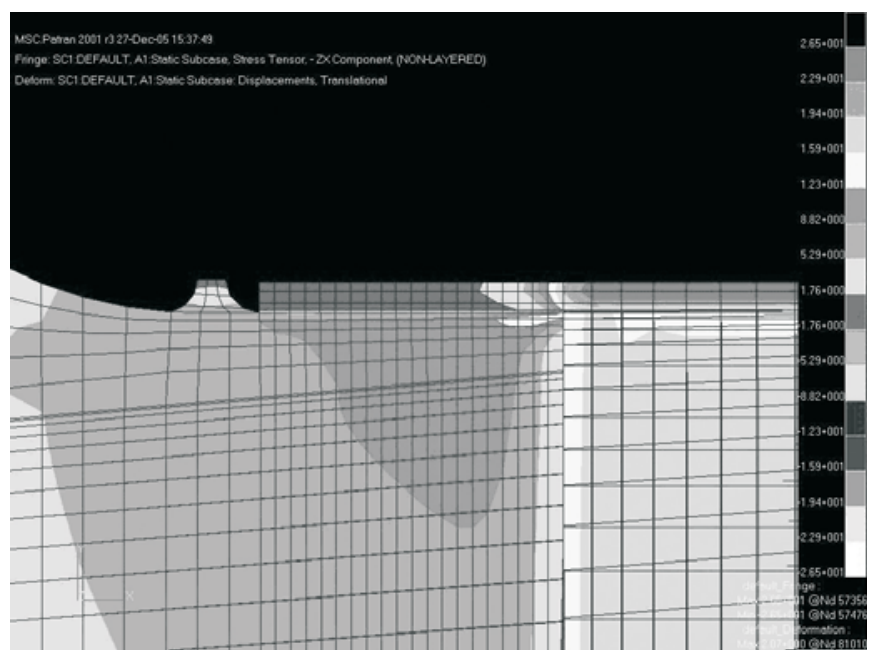

Fig. 7: Distribution of the shear stress in the Z-X direction. (See this picture for coordinate system)

Puck's criterion is one of the most complex strength criterion for composite materials analysis. This criterion distinguishes between the failure of fibres (FF) and interfibre failure (IFF) of the matrix or matrix-fibre interface. Puck's criterion passes when its values for all layers and for FF and IFF are less or equal than 1 . Details about Puck's criterion are in literature $[2,3]$.

Third failure case is the failure of adhesive bond between composite and metallic part. This bond was accomplished by Table 1: Comparison of main properties of designed shafts

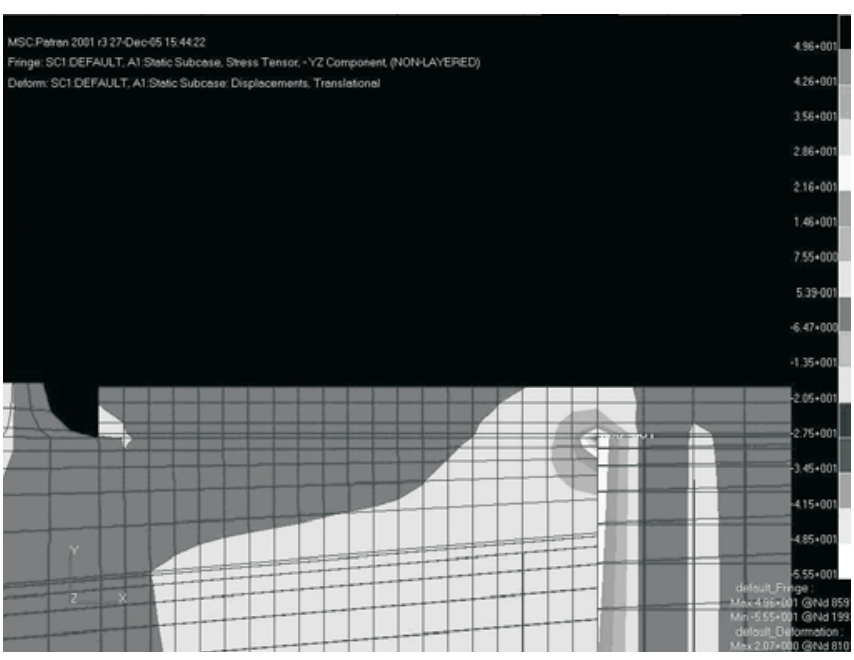

Fig. 8: Distribution of the shear stress in the Y-Z direction. (See this picture for coordinate system)

epoxi adhesive Spabond 345. We used FEM analysis to verify whether no failure occures in the adhesive. The value of 8 MPa is taken as allowable shear stress in the adhesive. The producer specifies the maximal stress of $35 \mathrm{MPa}$ which value is not exceeded even in the stress peaks. The FEA was accomplished only for version 3 , because steeper peeks are expected for this torsionaly less stiff shaft. Fig. 6 represents the section of FE mesh. Model of the metallic flange was simplified.

\section{Conclusion}

Table 1 concludes results for all three versions of driveshafts. First all metal shaft shows the medium longitudinal stiffness and the highest torsional stiffness and furthermore the highest weight from all shafts. These results are disadvantageous. Shaft version 2 is of relatively low axial stiffness and of still too high torsional stiffness. Shaft version 3 fulfills all conditions and is chosen for future tests.

\section{References}

[1] Rastogi, N.: Design of Composite Driveshafts for Automotive Applications. 2004-01-0485, SAE Technical Paper Series.

[2] Cuntze, R. G., Freund, A.: The Predictive Capability of Failure Mode Concept-Based Strength Criteria for Multidirectional Laminates, Composites Science and Technology Vol. 64 (2004), p. 343-377.

\begin{tabular}{|l|c|c|c|c|}
\hline \multicolumn{2}{|l|}{} & $\begin{array}{c}\text { Shaft version 1 } \\
\text { Al alloy }\end{array}$ & $\begin{array}{c}\text { Shaft version 2 } \\
\text { HSC/epoxi }\end{array}$ & $\begin{array}{c}\text { Shaft version 3 } \\
\text { HSC+HMC/epoxi }\end{array}$ \\
\hline Longitudinal Young's modulus & $\mathrm{GPa}$ & 73.0 & 63.8 & 182.7 \\
\hline Transversal Young's modulus & $\mathrm{GPa}$ & 73.0 & 9.8 & 39.0 \\
\hline Shear modulus of elasticity & $\mathrm{GPa}$ & 28.0 & 21.5 & 5.1 \\
\hline Longitudinal stiffnes (EI) & $\mathrm{N} \cdot \mathrm{mm}^{2}$ & $4.4 \times 10^{10}$ & $4.3 \times 10^{10}$ & $1.1 \times 10^{11}$ \\
\hline Torsional stiffnes (GJ) & $\mathrm{N} \cdot \mathrm{mm}^{2}$ & $3.3 \times 10^{10}$ & $2.9 \times 10^{10}$ & $5.9 \times 10^{09}$ \\
\hline Mass & $\mathrm{g}$ & 1564 & 923 & 916 \\
\hline
\end{tabular}


[3] Puck, A., Schrumann, H.: Failure Analysis of FRP Laminates by Means of Physically Based Phenomenological Models, Composites Science and Technology Vol. 58 (1998), p. 1045-1067.

[4] Puck, A., Kopp, J., Knops, M.: Guidlines for the Determination of the Parameters in Puck's Action Plane Strength Criterion, Composites Science and Technology, Vol. 62 (2002), p. 371-378.

[5] Agarwal, B. D., Broutman, L. J.: Vláknové kompozity, SNTL, 1987.

[6] Gay, D.: Matériaux composites, Hermes, 1997.

[8] Hoskins, B. C., Baker, A. A.: Composite Materials for Aircraft Structures, American Institute of Aeronautics and Astronautics, Inc., 1986.

[9] Kolář, V., Němec, I., Kanický, V.: FEM - principy a praxe metody konečných pruki̊, Computer Press, 1997.
[10] Uher, O.: Mathematical Modeling of Behavior of Filament Wound Composite Structures, ČVUT, 2002.

Ing. Robin Poul

e-mail: poulrobin@seznam.cz

Ing. Pavel Růžička

Doc. Ing. D. Hanus CSc.

Department of Automotive and Aerospace Engineering Ing. Karel Blahouš

Department of Mechanics

Czech Technical University in Prague

Faculty of Mechanical Engineering

Technická 4

16607 Prague 6, Czech Republic 